\title{
Fetal kidney length as a parameter for determination of gestational age in pregnancy
}

\author{
Nirmala Shivalingaiah ${ }^{1}$, Sowmya $K^{1 *}$, Ananya $\mathbf{R}^{1}$, Kanmani $\mathbf{T R}^{1}$, Marimuthu $\mathbf{P}^{2}$ \\ ${ }^{1}$ Department of Obstetrics \& Gynecology, KIMS Hospital and Research Centre, Bangalore, Karnataka, India \\ ${ }^{2}$ Department of Bio-statistics, NIMHANS, Bangalore, Karnataka, India
}

Received: 6 May 2014

Accepted: 23 May 2014

\section{*Correspondence:}

Dr. Sowmya K,

E-mail: drsowmyagopinath@gmail.com

(C) 2014 Shivalingaiah $\mathrm{N}$ et al. This is an open-access article distributed under the terms of the Creative Commons Attribution Non-Commercial License, which permits unrestricted non-commercial use, distribution, and reproduction in any medium, provided the original work is properly cited.

\begin{abstract}
Background: Establishing the gestational age of the fetus, especially in late trimester is a challenge to aptly treat the pregnant woman. Ultrasound parameters like BPD, HC, AC \& FL in second and third trimesters are not very reliable for dating the pregnancy. Fetal kidney length has been studied and shown to strongly correlate with the gestational age in late trimesters even in IUGR fetuses.

Methods: The present study evaluated the role of kidney length in determining the gestation age with the study population of 60 pregnant women between 24 - 36 weeks of gestation whose pregnancies were dated accurately by early dating scan. Length of the nearer kidney was measured in centimeters, 4 weekly in the longitudinal axis along with other biometric indices.

Results: According to the observations, the mean deviation from the gestational age at all the weeks is least for KL. The result indicates that the kidney length in the present study correlated well with the assigned gestational age and found almost same as all the ultrasound biometric parameters put together.

Conclusions: Kidney length can be used as an individual parameter in estimating gestational age, especially in later trimesters, where biometric indices may not be much reliable.
\end{abstract}

Keywords: Pregnancy, Kidney length, Ultrasound, Gestational age

\section{INTRODUCTION}

From time immemorial there has been search for a single ultrasonographic parameter to determine the appropriate gestation of the fetus which is not affected by IUGR. As accurate age of fetus plays a pivotal role in obstetric care, uncertain dates and no assigned ultrasound dates in early trimesters poses a dilemma in management decisions leading to iatrogenic pre or post maturities. In high risk pregnancies like preeclampsia, IUGR, GDM, planning termination of pregnancy due to complications or to plan for fetal investigations or therapy requires an accurate gestational age. There are number of parameters used to calculate gestational age, but most commonly used by all sonologists is a composite GA obtained by BPD, HC, AC
\& FL in second and third trimesters. Even these may not provide GA with great accuracy owing to the discrepancies in late trimester scans and IUGR.

Fetal kidney has been shown a steady growth of $1.7 \mathrm{~mm}$ fortnightly ${ }^{5}$ throughout pregnancy and is unaffected by growth abnormalities. Various studies have reported that fetal kidney length strongly correlates with the gestational age in late trimesters. Hence, this descriptive study was undertaken in the department of OBG, KIMS hospital, Bangalore to evaluate the application and accuracy of fetal kidney length measurement in determining the gestational age of the fetus as compared to that of other fetal biometric indices. 


\section{METHODS}

Sixty women with singleton normal pregnancies who were certain of their LMPs and whose pregnancies were accurately dated by an early dating scan were included after counseling and informed consent. Institutional Ethical clearance was obtained for the study. Study group women were registered and had their regular antenatal checkups and routine investigations and underwent fetal biometric and kidney length measurement at 24, 28, 32 \& 36 weeks of pregnancy.

Cases of oligohydramnios or polyhydramnios, dilated renal pelvis $(>4 \mathrm{~mm})$, chromosomal and congenital anomalies, abnormal renal morphology, obscure renal borders, multiple pregnancies, gross maternal obesity, GDM or early onset Preeclampsia were excluded from the study.

Imaging kidney even with high resolution USG machines may be difficult in early weeks of gestation. Hence in the present study, the kidney length has been taken as a bipolar measurement cautiously excluding the adrenals starting from 24 weeks of gestation. Kidneys were identified first in transverse section just below the level for $\mathrm{AC}$ measurement, and then the probe was rotated longitudinally till full length of kidney was identified. Average of 3 measurements in centimeters of the proximal kidney was recorded as final measurement. The measurements were performed using gray scale real time ultrasonographic scanner (Philips HD9) with 3.5-5 MHz curvilinear transducer.

Appropriate statistical analysis was done using SPSS version 2. Pearson's correlation was calculated for estimated gestational age and the measured gestational age by BPD, HC, AC, FL and KL.

\section{RESULTS}

Sixty women were selected to complete the study with the ages ranging from 18-34 years. There was no difficulty in identification of kidney and taking appropriate measurements.

Table 1: The relationship of gestational age and the various indices used for gestational age estimation between 2436 weeks including kidney length.

\begin{tabular}{|c|c|c|c|c|c|}
\hline & $\begin{array}{l}\text { SE (standard } \\
\text { error) }\end{array}$ & Mode & $\begin{array}{l}\text { SD (standard } \\
\text { deviation) }\end{array}$ & $\begin{array}{l}\text { MD (mean } \\
\text { deviation) }\end{array}$ & $\begin{array}{l}\text { CV (coefficient } \\
\text { variation) }\end{array}$ \\
\hline \multicolumn{6}{|c|}{ At 24 weeks } \\
\hline BPD & 0.082 & 23 & 0.633 & 1.22 & 2.77 \\
\hline $\mathrm{HC}$ & 0.211 & 23 & 1.635 & 1.27 & 7.19 \\
\hline $\mathrm{AC}$ & 0.198 & 24 & 1.533 & 1.17 & 6.47 \\
\hline FL & 0.080 & 22 & 0.622 & 2.05 & 2.84 \\
\hline KL & 0.070 & 24 & 0.541 & 0.32 & 2.23 \\
\hline \multicolumn{6}{|c|}{ At 28 weeks } \\
\hline BPD & 0.115 & 27 & .892 & 0.75 & 3.22 \\
\hline $\mathrm{HC}$ & 0.146 & 28 & 1.134 & 0.77 & 4.06 \\
\hline $\mathrm{AC}$ & 0.238 & 28 & 1.841 & 1.47 & 6.73 \\
\hline FL & 0.112 & 28 & 0.865 & 0.62 & 3.08 \\
\hline KL & 0.079 & 28 & 0.613 & 0.45 & 2.17 \\
\hline \multicolumn{6}{|c|}{ At 32 weeks } \\
\hline BPD & 0.134 & 31 & 1.039 & 0.87 & 3.32 \\
\hline $\mathrm{HC}$ & 0.239 & 35 & 1.851 & 2.68 & 5.35 \\
\hline $\mathrm{AC}$ & 0.184 & 32 & 1.429 & 1.10 & 4.52 \\
\hline FL & 0.172 & 34 & 1.331 & 2.70 & 3.84 \\
\hline KL & 0.126 & 33 & 0.976 & 1.02 & 2.97 \\
\hline \multicolumn{6}{|c|}{ At 36 weeks } \\
\hline BPD & 0.052 & 33 & 0.399 & 3.10 & 1.21 \\
\hline $\mathrm{HC}$ & 0.248 & 35 & 1.923 & 1.52 & 5.24 \\
\hline $\mathrm{AC}$ & 0.184 & 36 & 1.422 & 1.07 & 3.99 \\
\hline FL & 0.190 & 38 & 1.471 & 2.07 & 3.87 \\
\hline $\mathrm{KL}$ & 0.139 & 37 & 1.075 & 0.98 & 2.94 \\
\hline
\end{tabular}


Table 2: The mean and confident interval of measurements of various parameters at different gestational age.

\begin{tabular}{|c|c|c|}
\hline & Mean $(\mathrm{cm}) \pm \mathbf{S D}$ & $95 \% \mathrm{CI}$ \\
\hline \multicolumn{3}{|c|}{ At 24 weeks } \\
\hline BPD & $5.74 \pm 0.18$ & $5.70-5.79$ \\
\hline $\mathrm{HC}$ & $20.53 \pm 2.06$ & $20.00-21.06$ \\
\hline $\mathrm{AC}$ & $18.31 \pm 0.56$ & $18.17-18.46$ \\
\hline FL & $3.75 \pm 0.14$ & $3.71-3.78$ \\
\hline KL & $2.41 \pm 0.05$ & $2.40-2.43$ \\
\hline \multicolumn{3}{|c|}{ At 28 weeks } \\
\hline BPD & $7.38 \pm 0.30$ & $7.30-7.46$ \\
\hline $\mathrm{HC}$ & $26.11 \pm 1.05$ & $25.84-26.38$ \\
\hline $\mathrm{AC}$ & $23.32 \pm 1.15$ & $23.02-23.62$ \\
\hline FL & $5.26 \pm 0.17$ & $5.21-5.30$ \\
\hline KL & $2.82 \pm 0.06$ & $2.80-2.83$ \\
\hline \multicolumn{3}{|c|}{ At 32 weeks } \\
\hline BPD & $8.58 \pm 0.33$ & $8.50-8.67$ \\
\hline $\mathrm{HC}$ & $31.49 \pm 1.18$ & $31.19-31.80$ \\
\hline $\mathrm{AC}$ & $29.61 \pm 1.23$ & $29.29-29.93$ \\
\hline FL & $6.60 \pm 0.25$ & $6.53-6.66$ \\
\hline KL & $3.28 \pm 0.09$ & $3.26-3.30$ \\
\hline \multicolumn{3}{|c|}{ At 36 weeks } \\
\hline BPD & $9.11 \pm 0.13$ & $9.08-9.15$ \\
\hline $\mathrm{HC}$ & $32.71 \pm 1.09$ & $32.43-32.99$ \\
\hline $\mathrm{AC}$ & $32.48 \pm 0.99$ & $32.23-32.74$ \\
\hline FL & $7.24 \pm 0.26$ & $7.17-7.30$ \\
\hline KL & $3.65 \pm 0.09$ & $3.62-3.67$ \\
\hline
\end{tabular}

Table 1 indicates the mean of gestational age determined by all the parameters including KL. According to the observations, the mean deviation from the gestational age at all the weeks is least for KL, except at 32 weeks which shows a mean deviation of 0.87 for BPD as compared to $\mathrm{KL}$ which is 1.02 . It can be concluded that KL estimates the gestational age at any given gestation with the least deviation from the mean and is a reliable parameter except at 32 weeks. We know from Table 2 that the standard deviation and the $95 \%$ confident interval of the measurements for $\mathrm{KL}$ are the least at all gestations indicating the reliability of $\mathrm{KL}$ for estimation of gestational age at all gestational ages. Also, the renal length of the fetus at any given gestation in millimeters almost corresponds to the gestational age of the fetus. This also helps in easy estimation of gestational age without any software or formulas.

Figure 1 shows maximum number of women were between 24-28 years of age (62\%) and which was the highest number of the study, wherein 29-34 age group was lowest in number among the subjects selected for the study. Figure 2 shows that both primigravida and multigravida were included in the study and primigravida $(70 \%)$ was the highest frequency compared to multigravida $(30 \%)$. The gestational age was calculated by Hadlock formula using BPD, $\mathrm{HC}, \mathrm{AC}$ and $\mathrm{FL}$ in centimeters. Renal length was measured in centimeters at
4 weekly intervals from 24-36 weeks. As Figure 3 shows, KL has consistent estimation of gestational age as compared to all the parameters.

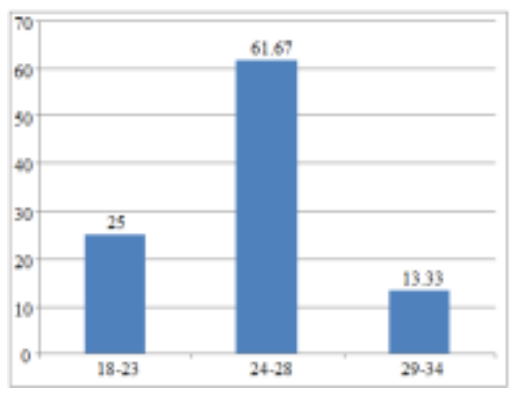

Figure 1: Age distribution of the subjects in the study, $\mathrm{N}=60$.

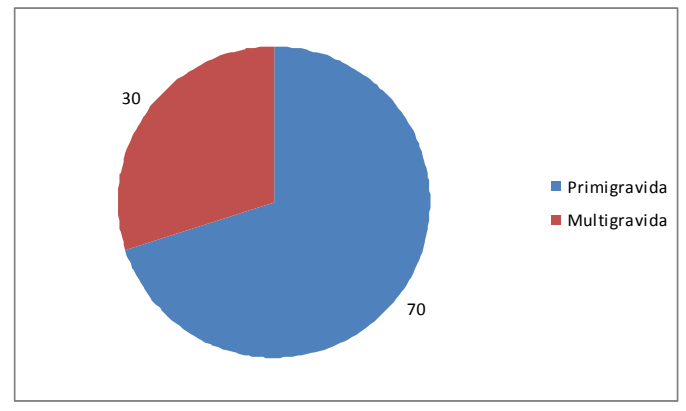

Figure 2: Distribution of parity.

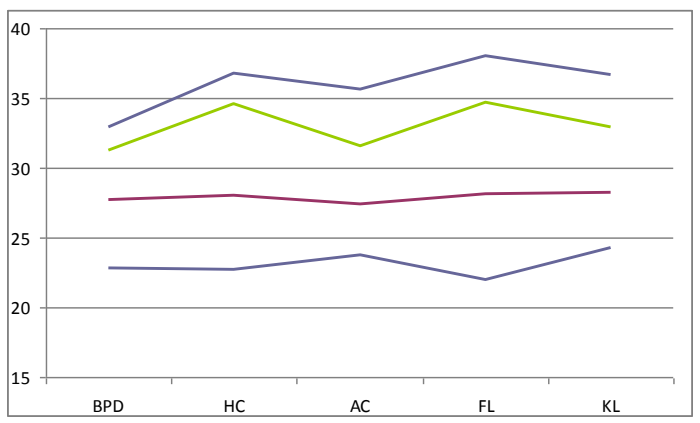

Figure 3: Mean of BPD, HC, AC, FL and $\mathrm{KL}$ at different gestations.

Pearson's correlation was calculated for estimated gestational age and the measured gestational age by BPD, $\mathrm{HC}, \mathrm{AC}, \mathrm{FL}$ and KL. It is observed that all the parameters are highly correlated $\left(\mathrm{r}^{2}=0.85-0.98, \mathrm{P}<0.05\right)$. However, it was found that $\mathrm{AC}$ is not correlating between these measurements and also, FL at 24 weeks and BPD at 36 weeks were poorly correlated.

\section{DISCUSSION}

The present day challenge in dating pregnancy is to find a method which is simple, easy to define and reproducible. Growth variation in the fetus affects all organs including the kidney but only in the AP and transverse diameter not the length. ${ }^{1,2}$ Earlier work found fetal kidney is easy to 
identify, ${ }^{1,2}$ but, Duval et al. $^{4}$ encountered difficulty in imaging kidney in breech presentation and in vertex presentation with back facing laterally or posteriorly. There was no problem in identifying, measuring and reproducing the same measurement of kidney length in the present study. As the differences between measurements of the left and the right kidney are minimal, ${ }^{2,3}$ measurement of one side kidney is reliable. In addition, sex of the fetus did not alter the measurements of the fetal kidney. ${ }^{7}$ Thus, in the present study single proximal kidney was measured without consideration to fetal sex. The kidney length in the present study correlated well with the assigned gestational age and found almost same as all the parameters put together. This provides an obvious advantage where there is difficulty in measuring BPD, HC due to engaged head or small AC due to IUGR. In such circumstances KL can be used on its own to estimate gestational age accurately.

The KL measurements in our study have been compared with other studies as shown in Table 3. The measurement compare well with the study by Konje et al. ${ }^{7}$ but more than those reported by Kansaria $\mathrm{JJ}$ et al. ${ }^{5}$ and less compared to Indu Kaul et al. ${ }^{6}$ These can be explained by the difference in ultrasound machines, number of operators, type of study and the region of study.

Table 3: Comparison between the mean KL of the study with other studies.

\begin{tabular}{|c|c|c|c|c|}
\hline $\begin{array}{l}\text { Gestational } \\
\text { age } \\
\text { (by weeks) }\end{array}$ & $\begin{array}{l}\text { Mean } \\
\text { fetal } \\
\text { KL in } \\
\text { the } \\
\text { present } \\
\text { study } \\
(2013) \\
(\mathrm{mm})\end{array}$ & $\begin{array}{l}\text { Mean } \\
\text { fetal } \\
\text { KL in } \\
\text { the } \\
\text { study } \\
\text { by } \\
\text { Konje } \\
\text { et al. } \\
2002 \\
(\mathrm{~mm})\end{array}$ & $\begin{array}{l}\text { Mean } \\
\text { fetal KL } \\
\text { in the } \\
\text { study by } \\
\text { Kansaria } \\
\text { JJ et al. } \\
2009 \\
(\mathrm{~mm})\end{array}$ & $\begin{array}{l}\text { Mean } \\
\text { fetal } \\
\text { KL in } \\
\text { the } \\
\text { study } \\
\text { by Indu } \\
\text { Kaul et } \\
\text { al. } 2012 \\
\text { (mm) }\end{array}$ \\
\hline 24 & 24.1 & 24.2 & 23.87 & 25.73 \\
\hline 28 & 28.2 & 29.0 & 26.98 & 31.52 \\
\hline 32 & 32.8 & 33.2 & 30.80 & 36.50 \\
\hline 36 & 36.5 & 38.2 & 34.26 & 40.58 \\
\hline
\end{tabular}

The present study found a strong Pearson's correlation ( $\mathrm{r}$ $=0.85-0.98, \mathrm{P}<0.05)$ for all the biometric parameters including KL which compared with other studies like Cohen et al. ${ }^{3} 1991(\mathrm{r}=0.82)$, Konje et al. $2002^{7}(\mathrm{r}=$ $0.91)$.

All the previous studies conclude that KL can be used to accurately date the pregnancy in difficult situations (engaged head, fetal IUGR, macrosomia, malformation etc.). The present study also reveals that KL can be used in the estimation of gestational age in combination with $\mathrm{BPD}, \mathrm{HC}, \mathrm{AC}$ and FL for better prediction and where dates are uncertain and the women present late for ultrasound biometry dating. The present study concludes that $\mathrm{KL}$ is a good indicator of gestational age.

The limitations of this study were the size of population and unable to compare the pre and post pregnancy renal lengths. Larger study population is required, to improve the accuracy of the values which are obtained. Only the length of proximal kidney was taken wherein measurements of both the kidneys would have been appropriate.

\section{ACKNOWLEDGEMENTS}

We express our sincere gratitude to Kempe Gowda Institute of Medical Sciences and Research Centre for allowing us to conduct this study. We would like to thank all the subjects who participated in this study.

Funding: No funding sources

Conflict of interest: None declared

Ethical approval: The study was approved by the institutional ethics committee

\section{REFERENCES}

1. Konje JC, Bell SC, Morton JJ, de Chazal R, Taylor DJ. Human fetal kidney morphometry during gestation and the relationship between weight, kidney morphometry and plasma active remain concentration as birth. Clin Sci. 1996;91:169-75.

2. Konje JC, Okara CL, Bell SC, de Chazal R, Taylor DJ. A cross-sectional study of changes in fetal renal size with gestation in appropriate and small for gestational age fetuses. Ultrasound Obstet Gynecol. 1997;9:35-7.

3. Cohen HL, Cooper J, Eisenberg P, Mandel FS, Gross BR, Goldman MA, Barxel E, Rawlinson KF. Normal length of fetal kidney: sonographic study of 397 obstetric patients. Am J Roentgenol. 1991;157:545-8.

4. Duval JM, Milon J, Langella B, et al. Ultrasonographic anatomy and physiology of the fetal kidney. Anat Clin. 1985;7(2):107-23.

5. J. J. Kansaria, S. V. Parulekar. Nomogram for fetal kidney length. Bombay Hosp J. 2009;51(2):155-62.

6. Indu Kaul, Vinay Menia, Amandeep K Anand, Renu Gupta. Role of fetal kidney length in estimation of gestational age. JK Sci J. 2012 Apr-Jun; 14(2):65-9.

7. Konje JC, Abrams KR, S. C. Bell, D. J. Taylor. Determination of gestational age after $24^{\text {th }}$ week of gestation from fetal kidney length measurement. Ultrasound Obstet Gynecol. 2002;19:592-7.

DOI: $10.5455 / 2320-1770 . i j r \operatorname{cog} 20140628$

Cite this article as: Shivalingaiah N, K Sowmya, R Ananya, TR Kanmani, P Marimuthu. Fetal kidney length as a parameter for determination of gestational age in pregnancy. Int $\mathrm{J}$ Reprod Contracept Obstet Gynecol 2014;3:424-7. 